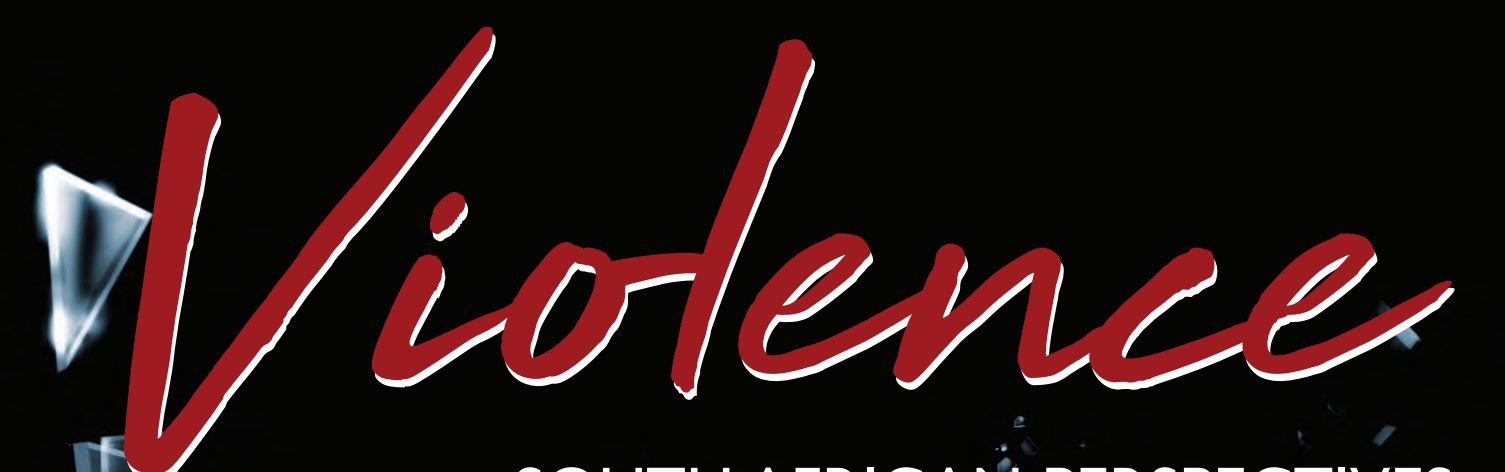

SOUTH,AFRICAN PERSPECTIVES

$\rightarrow$

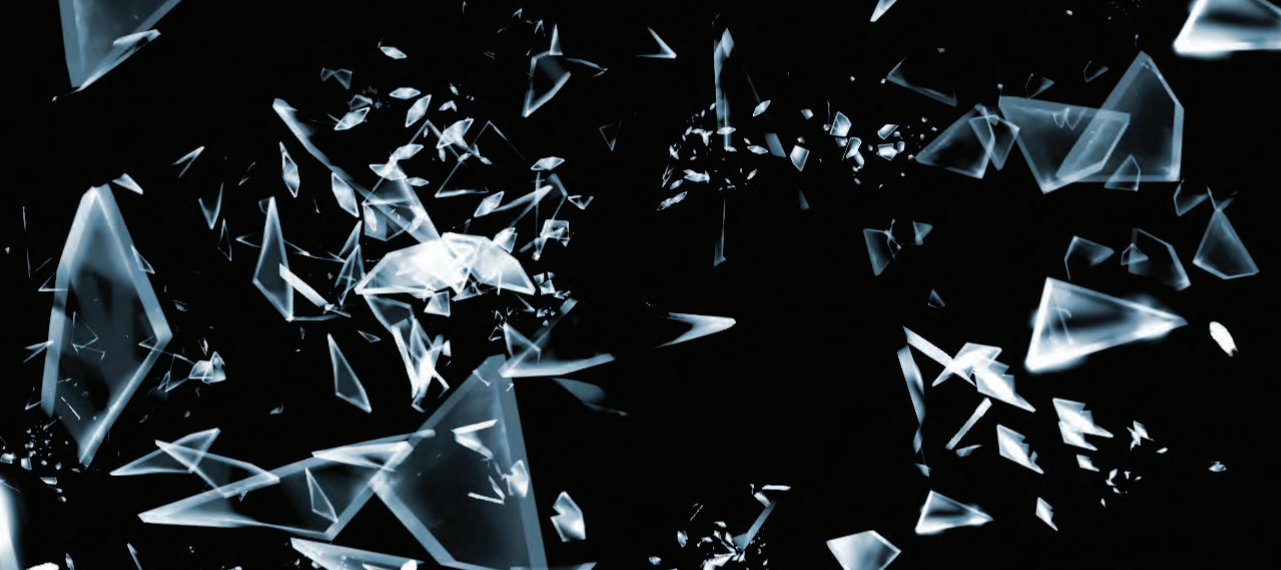

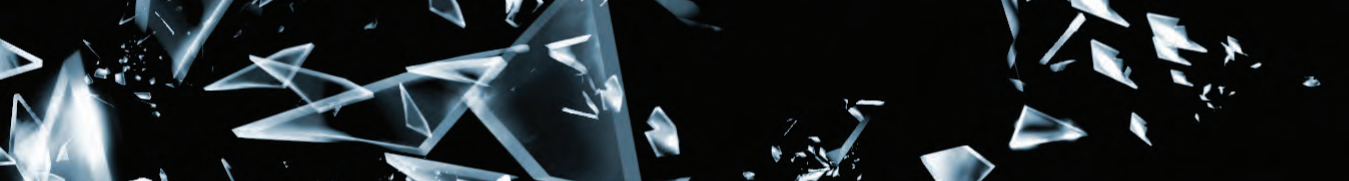

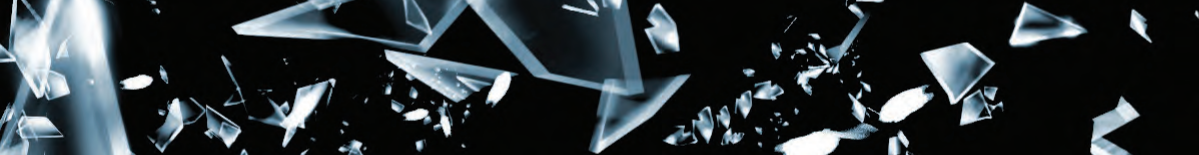

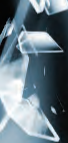

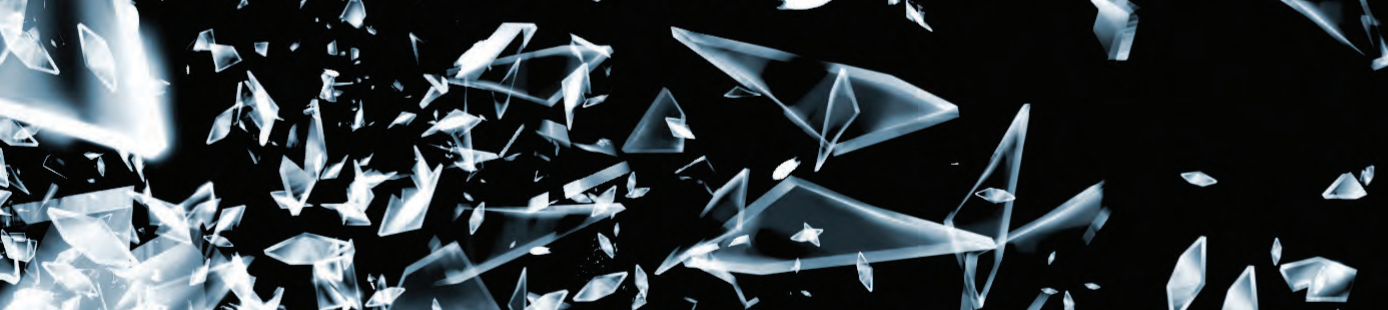

,

a 4 < 6

QX

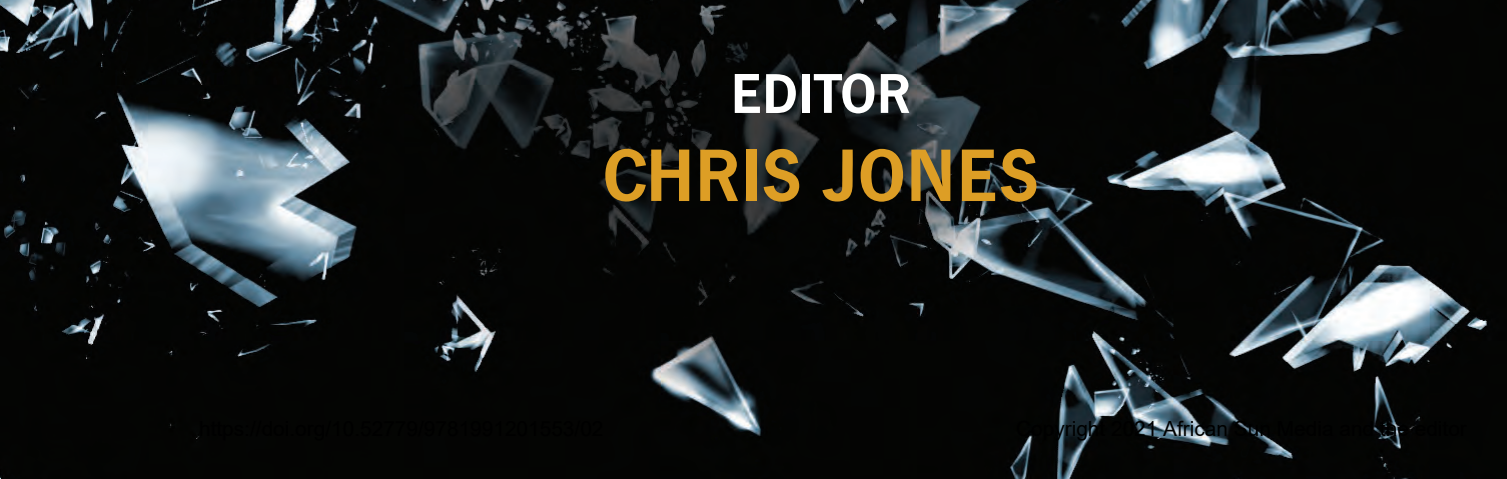




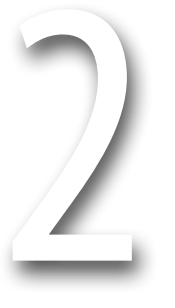

\section{VIOLENCE AGAINST CHILDREN: A STRONG MORAL COMMITMENT \\ IS NEEDED}

Chris Jones

\section{Keywords}

children; culture; faith-based communities; moral commitment; patriarchy; violence (physical, sexual and emotional)

\section{INTRODUCTION}

In South Africa, children are exposed to and experience high levels of physical, sexual, verbal, and emotional violence, as well as neglect. Families and households, despite all the potential locked up within them, are often the people and spaces with whom and where children are the most vulnerable. This violence is often silenced and becomes a socialised pattern for parents and children with certain long-term consequences, especially for the child. Many children's physical integrity is affected by violence, and they are thus deprived of opportunities to grow, prosper, and live to their full potential.

Following a qualitative methodological research approach, the chapter starts with a global and South African perspective on violence against children. It then looks at how violence is often rooted in patriarchy and culture, following by the fact that legislation alone is not enough, but that a stronger moral commitment is needed by all the different role players - such as faith-based communities, politicians, households, caregivers, and schools - in combating this multipronged pandemic.

The chapter is based on the intellectual richness and research by numerous local and international scholars, studies, and institutions over an extended period of time regarding violence against children (and women). It will be restricted to a broad perspective on this extremely important topic by referring to physical, sexual, and emotional violence, child neglect, as well as its long-term consequences, not only in the lives of children, but also on the economy, and public health and well-being. Unfortunately, due to a lack of space, it would not focus on other important issues, such as South African legislation protecting children (although I do refer to some important legislation later in the chapter); corporal punishment; ${ }^{1}$ children "residing

1 See Grobbelaar \& Jones (2020:67-96). 
with a genetically unrelated adult" 2 who consequently face "an increased likelihood of maltreatment" (Herring 2014:54); violence against children during lockdown; violence of the abandonment of children; violence of societies' prejudice, stigma, and discrimination against children with LGBITQ+ parents; $^{3}$ as well as protecting children regarding social media ${ }^{4}$ and violence in advertisements, ${ }^{5}$ to name a few.

\section{GLOBAL AND LOCAL PERSPECTIVES}

According to the World Health Organization (WHO) (2020:n.p.), “[v]iolence against children includes all forms of violence against people under 18 years old, whether perpetrated by parents or other caregivers, peers, romantic partners, or strangers". The United Nations International Children's Emergency Fund (UNICEF), which is a United Nations (UN) agency responsible for providing humanitarian and developmental aid to children, pointed out that, in 2017, nearly 300 million 2-4 year-olds were subjected to violent discipline on a regular basis (UNICEF 2017:7). According to Humanium (2021:n.p.), an international child sponsorship non-governmental organisation (NGO) dedicated to stopping violations of children's rights throughout the world, "there are more than 2.2 billion children on Earth. Nearly two billion of these live in a developing country". The WHO (2020:n.p.) estimates in this regard that, globally, "up to 1 billion children [almost half of the world's children] aged 2-17 years, have experienced physical, sexual, or emotional violence or neglect in the past year" (also see Hillis, Mercy, Amobi \& Kress 2016).

The WHO (ibid:n.p.) further says that "[e]xperiencing violence in childhood impacts lifelong health and well-being", and Target 16.2 of the 2030 Agenda for Sustainable Development asks to "end abuse, exploitation, trafficking and all forms of violence against, and torture of, children" (Council of Europe: 2017:n.p.). According to the WHO (2020:n.p.), "evidence from around the world shows that violence against children can be prevented".

A 2018 study by The Economist Intelligence Unit conducted in 40 countries, including South Africa, shows that only a very small percentage of children who experience sexual violence ever receive professional help. In nine out of ten cases of sexual abuse, the perpetrator is known to the child victim (The Economist Intelligence Unit 2020:7; Palm 2020:36). "Every day, across all countries and levels of society, millions of girls and boys face the alarmingly common childhood experience of sexual abuse and exploitation" (The Economist Intelligence Unit 2020:7) says Amina Mohammed, UN

2 See Herring (2014:54-61); Pew Research Center (2011) and Jones (1997:1117-1242).

3 See Knight, Stephenson, West, Delatycki, Jones, Little, Patton, Sawyer, Skinner, Telfer, Wake, North \& Oberklaid (2017), pp.1-3; Dempsey (2013); Crouch, McNair \& Waters (2016:499-505); Crouch, Waters, McNair \& Davis (2014:635).

4 See Fourie (2020:230-272).

5 See Vijayalakshmi (2015). 
deputy secretary general. "However, the adverse effects of sexual violence in childhood on health and mental wellbeing carry into adulthood, foreshadowing societal and public health risks that, like abuse itself, remain largely overlooked" (ibid 2020:7).

Violence against children is a "silent emergency of our time", UN secretary general Antonio Gutierrez maintained, and "sexual exploitation is one of its most egregious manifestations" (African Child Policy Forum 2020:n.p.).

A study conducted by the NGO, Save the Children ${ }^{6}$ (2017:1), found that

one in five children (19.8\%) [in South Africa] had experienced sexual abuse, compared to $12.7 \%$ in the global average; ${ }^{7}$ one in three (34.4\%) had experienced physical abuse, notably higher than the global average of $22.6 \% ;{ }^{8}$ one in six (16.1\%) reported experiencing emotional abuse; one in eight (12.2\%) reported being neglected; and one in six (16.9\%) reported witnessing violence.

Working with international experts to "investigate the impact of violence experienced during childhood on our society and its overall burden on our economy" (ibid:1), this study shows that

compared to individuals who did not experience sexual violence as a child, individuals who did experience sexual violence as a child are $323 \%$ more at risk of drug abuse and $284 \%$ more at risk of self-harm. Similarly, individuals who were physically abused as children are $157 \%$ more at risk of being diagnosed with anxiety at some point in their lives, 155\% more at risk of alcohol abuse, 146\% more at risk of drug abuse, and $118 \%$ more at risk of perpetrating interpersonal violence at some point in their lives.

Individuals who were emotionally abused as children are 138\% more at risk of being diagnosed with a serious mental illness and 141\% more at risk of drug abuse at some point in their lives. Individuals who were neglected as children are $173 \%$ more at risk of being diagnosed with anxiety.

(lbid:1-2)

This points to the reality that "children who experience violence are set on a life trajectory that is filled with substantially higher risks, preventing them from reaching their full human potential" (ibid:2).

These scholars further examined "the reductions in negative outcomes we could make in our society if children in South Africa did not experience violence" (ibid:2). They write that

if children in South Africa did not experience sexual violence, depression in women could be reduced by $6 \%$, anxiety in the entire South African population could be reduced by $6 \%$, alcohol abuse could drop by $7 \%$ in men and $10 \%$ in women, drug abuse could be reduced by $14 \%$ in the entire population, STDs

\footnotetext{
6 See Burton, Ward, Artz \& Leoschut (2016).

$7 \quad$ Also see World Health Organization (2006).

8 Also see Stoltenborgh, Bakermans-Kranenburg \& Van Ijzendoorn (2013).
} 
by $35 \%$ in the entire population and $8 \%$ in women, HIV by $5 \%$ in women, interpersonal violence by $3 \%$ in men and $7 \%$ in women, and self-harm by $12 \%$ in the entire population.

(Ibid:2)

This study also estimated "the cost of the negative impacts of violence against children on our economy" (ibid:3). It found that "in 2015, violence against children cost the South African economy R238.58 billion, or 5.93\% of the GDP" (ibid:3). It states that we "now have evidence to demonstrate that by preventing children from experiencing violence we are contributing to building a healthier society and a stronger economy in South Africa" (ibid:4). In this regard, Elsabé Brits refers to the Child Gauge (CG) 2018: Children, Families and the State study which says that although there is "growing evidence on the extent, causes, and social and economic costs of violence against women and children" (Brits 2018:n.p.), this is not a high political priority.

Despite repeated commitments to end violence against women and children at the highest level there is a lack of genuine political will and the country's response is grossly inadequate. Addressing violence against women and children should be a political priority and we should adopt an approach that recognises that this problem affects every community, every family and every child.

(Ibid:n.p.)

In South Africa specifically, child abuse and neglect have become endemic. A study of 2000 children over a period of 22 years (Richter, Matthews, Kagura \& Nonterah 2018) focused on violence against children and showed that it "is a significant cause of personal suffering and long-term ill health, poor psychological adjustment, and a range of social difficulties, including adverse effects intergenerationally" (ibid:181). This study found amongst others that over

the past two decades, only $1 \%$ of the sample had not been exposed to or experienced violence in their home, school and/or community. Two-thirds of children of school going age were reported as having been exposed to community violence, and more than half of all children to violence in their home. Reports of sexual violence increased from 10\% among primary schoolaged children to $\sim 30 \%$ among adolescents and young adults. Over the course of their lives, $\sim 40 \%$ of children were reported as having been exposed to or being victims of five or six of the categories of violence coded in this analysis. High levels of violence perpetration were reported across childhood. Age and gender differences in exposure to and experience and perpetration of violence were evident, and all categories of violence were more prevalent among poorer and more disadvantaged groups.

(Ibid:181)

Amongst some of the conclusions of this study focusing on the "longitudinal perspective on violence in the lives of South African children from the Birth to Twenty Plus cohort ... in Johannesburg-Soweto" (ibid:181-186) are "[v]ery high levels of violence were reported in all the settings of urban South African children's lives: home, community, school, among peers and in their intimate relationships". It further 
concludes that the "personal and social costs of violence are very high, resulting in major public health problems due to its avoidable effects on short- and long-term mental and physical health and social adjustment, and intergenerationally" (ibid:181).

In 2016, the Research Bulletin, Optimus Study 9 (Burton, Ward, Artz \& Leoschut 2016:2), found that "[o]ne in five young people reported having experienced some form of sexual abuse in their lifetimes, and this was true of both boys and girls. This rate is higher than the global average, ${ }^{10}$ but no worse than the highest rates identified in studies from Australia and other countries in Africa."11 This study looked into different forms of sexual abuse, such as adolescents who "had been exposed to coerced (unwanted or by force) and consensual sexual touching, exposure to intimate body parts or pornographic images, sexual harassment, penetrative and nonpenetrative sexual intercourse (actual or attempted), by or with an adult or similaraged peers" (ibid:2).

Although boys and girls were exposed to similar rates of sexual abuse, "girls were more likely to experience forced and penetrative sexual abuse, and other forms of sexual abuse that involve contact with the abuser, while boys were more likely to report forced exposure to sexual acts and material" (ibid:2). Young people reported that it was more likely being "abused by adults they knew than by adult strangers, but they were most likely to have been abused by a fellow child or teen than by any adult" (ibid:2).

With regards to physical abuse, one in three ${ }^{12}$ young people reported that they have experienced physical abuse, such as being hit, beaten, and/or kicked by an adult caregiver; "although it was more likely to be reported by girls, and by coloured and black respondents, than by boys, or white or Indian respondents" (ibid:2). With regards to emotional abuse, meaning that respondents at any point in their lifetime got scared or felt really bad because grown-ups (adults) in their lives called them names, said

9 "The study sample was stratified by households and schools. Within households, a total of 5635 adolescents between the ages of 15 and 17 years were interviewed, of whom four out of five (75\%) were black, just over one in ten (13.7\%) were coloured, $7.4 \%$ were white, and 3.9\% were Indian. Males were slightly overrepresented, accounting for $55.7 \%$ of the sample, while females constituted $44.3 \%$. Just over one-third (35.1\%) of the young people lived in metropolitan areas, $35.1 \%$ in urban areas, and $31.6 \%$ in rural areas. Almost all (96.6\%, or 5444 individuals) were attending school. In schools, a total of 4095 young people were interviewed, of whom $87 \%$ were black, one in ten (10.1\%) were coloured, $1.5 \%$ were white, and $1.3 \%$ were Indian. Just over half (51.7\%) were male, while females constituted $48.3 \%$ of the schools' sample. Almost half $(46.8 \%)$ of those interviewed were in metropolitan areas, with just over one-quarter (27.9\%) being in rural areas and one-quarter (25.3\%) in urban areas" (Burton, Ward, Artz \& Leoschut 2015:5).

10 WHO (2006)

11 Ibid.

12 "A meta-analysis of rates of physical abuse around the world found that, on average, $22.6 \%$ of study participants reported having experienced physical abuse. Rates reported in this nationwide prevalence study are therefore considerably higher than the global average" (Burton, Ward, Artz \& Leoschut 2015:17); also see Stoltenborgh et al. (2013). 
mean things to them, or said that they didn't want them, a "total of $16.1 \%$ of young people reported experiencing this, and girls reported higher rates than boys" (ibid:2).

Two forms of child neglect ${ }^{13}$ were explored, namely whether "the respondent had ever had to live in a home that was broken down, unsafe or unhealthy; and whether there was ever a time when his/her parents did not care if he/she was clean, wore clean clothes, or brushed their teeth or hair", one fifth of the respondents indicated that they have experienced one of these forms of neglect. "Girls reported higher rates of neglect than boys, and black and coloured respondents reported higher rates than Indian and white respondents" (ibid:2).

According to research (Burton et al. 2016:59; Palm 2020:38), it is difficult to change behaviour because abuse is considered culturally acceptable by many people. In a regional study in the Eastern Cape (Jewkes, Dunkle, Ndunad, Jamaa \& Purene 2010:833; Palm 2020:38), 90\% of boys and girls indicated they were beaten by their caregiver before the age of 18 .

\section{ROOTED IN PATRIARCHY AND CULTURE}

South Africa's violent colonial and apartheid history has left a legacy and culture of violence that continues to play out in households, care, schools, and communities (Palm 2020:38). Patriarchal households often perpetuate this violence (Palm 2020:39; Mathews 2018 n.p.; Miller 2019 n.p.). In South Africa, as in many other places in the world,

social and cultural norms promote a gendered hierarchy: men are in a superior position over women and children. These social norms provide considerable space for men's violence towards women and children to be tolerated. They are manifested in expressions of masculinity, enforcement of gender norms and the way that children are disciplined. ～(Mathews 2018:n.p.; also see Hall, Richter, Mokomane \& Lake 2018; Brits 2018:n.p.)

According to Mathews (2018:n.p.), evidence shows

that men's use of violence and controlling behaviour towards an intimate partner often extends to physically punishing their children as a means of discipline. Importantly, research is now revealing ${ }^{14}$ that women who experience violence at the hands of a partner are more likely to use physical punishment to discipline their children. This further drives the cycle of intergenerational violence.

Mathews (ibid:n.p.) confirms the views of The Economist Intelligence Unit and Save the Children referred to above, namely that " $[\mathrm{t}]$ he impact of experiencing or

13 "Neglect has consequences for children, consequences that are as serious as any other form of child abuse". For more information see Burton, Ward, Artz \& Leoschut (2015:14); Hall \& Sambu (2001); Kotch et al. (2008); Manly et al. (2001).

See Fulu, McCook \& Falb (2017). 
witnessing violence as a child has wide-ranging and long lasting effects. When a child experiences violence at home, they learn to tolerate violence". She then makes the important point that these children "are also at an increased risk of suffering from poor mental health, engaging in drug and alcohol abuse and risky sexual behaviours, and contracting HIV. They are also more at risk of behavioural problems such as aggression, delinquency and poor social functioning" (ibid:n.p.).

Children exposed to violence "are more likely to lack empathy towards others. That means they're more likely to perpetrate violence" (ibid:n.p.), and intergenerational transmission of violence is driven in this way which "has a direct impact on their relationships with intimate partners, as well as their ability to be emotionally responsive parents" (ibid:n.p.). If one grows up in a violent household, it "affects a child's sense of security, self worth and how they relate to other children" (ibid:n.p.).

The child homicide rate in our country is double that of the world average. About half of these occur in the context of home-related child abuse and neglect, with children under four being the most vulnerable (Palm 2020:39; Röhrs 2019:5; Mathews \& Martin 2016:1160). Almost half of South African children indicated that they had already witnessed how their mother experienced some form of violence in their home (Palm 2020: 39; Jamieson, Mathews \& Röhrs 2018:82). And it is precisely this exposure, as we have seen above, that gives rise to further patterns of violence. Boys who experience violence as a child can especially become a perpetrator of violence later in life.

There are studies (Palm 2020:39; Mathews \& Benvenuti 2014:31; Jewkes et al. 2010:833) proving that an estimated 40\% of reported sexual crimes in South Africa occur with children, while one in three women and one in five men have reported being sexually abused before the age of 18 . An "estimated $6 \%$ of girls get married while younger than 18 years, and 1\% of girls while younger than 15 years" (Le Roux 2020:169; Department of Health 2007).

Women are often the primary caregivers of children and therefore (in the light of the above statistics) of the main perpetrators of early domestic violence against children. This is often a displaced aggression cycle where women, because they are often the victims of domestic violence, vent their frustration on their children or those in their care - a case of men punishing women and women punishing children (Palm 2020:42; Jones 2019:14). Social norms (Jamieson et al. 2018:38) and family attitudes and beliefs that support and perpetuate violence in various ways must be stopped. Unfortunately, violence against children is complicated by religious and cultural justifications, with their roots strongly grounded in patriarchy. According to this, women and children are considered inferior, and children as the possessions or property of their parents. Society must (more and more) do away with exclusive male power, control, and domination. Beliefs - such as those that children are at the bottom of the hierarchy 
of value in households and communities; and that adults are higher up in value and therefore able to fully decide on the child's life and how they should be treated should be stopped (Palm 2020:42-43; Jones 2019:14).

\section{LEGISLATION IS NOT ENOUGH}

Corporal punishment (see Grobbelaar \& Jones 2020:67-96) has been identified as a key driver of the high levels of violence against children in South Africa. In the light of this, the recent ruling by the Constitutional Court banning corporal punishment in South Africa is a very positive development. "On 18 September 2019, the Constitutional Court of South Africa ruled that the defence of 'reasonable and moderate chastisement' was unconstitutional. This effectively means that all corporal punishment of children was banned" (ibid:76). It will hopefully help to change and improve endemic norms and practices regarding violence, especially in households.

"In 1995, South Africa ratified the Convention on the Rights of the Child and embodied it in the Children's Act and other national legislation" (Palm 2020:37). According to Chapter 2 of our Constitution, Section 28(1)(d), "[e]very child has the right ... to be protected from maltreatment, neglect, abuse or degradation" (The Constitution 1996:13). While legislation is necessary, it is obviously not enough. What is needed, is much stronger moral commitment by South Africans in all spheres of life to stop violence against children and women.

Although legislation is generally very important in protecting children against violence, Herring (2014:53) (School of Law, University of New Mexico) brings the following perspective to the fore. He believes that legislation is normally reactive and explains it as follows:

Public child welfare systems and child welfare laws are designed to address the risk of violence faced by children. Although preventive approaches exist, the primary legal approach is reactive. The law presumes that a child's adult caretakers are at least minimally adequate parents. Thus, child welfare laws allow the state to intervene to protect children only after there is reason to believe that a particular child has suffered some form of harm and is likely to suffer additional harm.

In addition, once a child is victimized, public child welfare systems seek to secure the child's well-being. The system must construct the child's living situation in a way that protects the child from further violence and produces acceptable outcomes in terms of the child's development. Each of these two facets of the child welfare endeavor places a premium on the assessment and prediction of human behavior.

South Africa has also recently launched an extensive curriculum for sex education ${ }^{15}$ in schools (2019) which aims, amongst other things, to prevent sexual abuse and

15 See Department of Basic Education (2019). 
exploitation of children by equipping them with more information and life skills. It should strengthen many children's resistance to sexual abuse, as well as their readiness to report abuse, and their ability to protect themselves from abuse and exploitation. Unfortunately, both these developments were met with opposition. For example, some religious leaders have asked their members not to obey the law on the abolition of corporal punishment. However, a much stronger inner conviction will have to be built so that violence against children and women can in no way be justified.

The complex interplay of various factors leading to this violence needs to be tackled with even greater seriousness, and all potential role players will need to work more actively on a common agenda on how to do this best (discussed later). This requires, in particular, as noted earlier, much stronger political will and ethical leadership (Jones 2019:14).

\section{FAITH COMMUNITIES CAN MAKE A DIFFERENCE ${ }^{16}$}

We know churches are the institutions most trusted by South Africans, and this makes them an important agent of change, also in terms of violence. But then, for example, the literal understanding of certain biblical texts (for Christians) that would justify corporal punishment must be revised responsibly. The abuse of texts from an ancient, cultural environment as if it were just as applicable today - especially with regards to punishment of children - can so easily leave children voiceless and invisible.

Faith communities can make a big difference. In 2017, an Ipsos Mori poll (Ipsos 2017:n.p.; Grobbelaar \& Jones 2020:82) found that 88\% of South Africans indicated that religion is an important part of their lives. When one considers this, one realizes what a huge impact religious leaders and believers can make on addressing violence through spiritual capital on an individual level, but also in families, communities, institutions, and the wider society. Unfortunately, this does not happen efficiently at all, especially if one looks at the above statistics. More is needed.

\section{SEEKING FURTHER SOLUTIONS}

According to the Optimus Study (Burton, Ward, Artz \& Leoschut 2015:3), the following measures of prevention and intervention need to be addressed and strengthened "[w] here a child has experienced abuse or neglect, services need to be put in place to ensure that the child is safe and can receive the necessary physical and mental health treatment, so that the child victim is able to recover" (ibid:3). Furthermore, according to this study,

services also need to be in place to ensure that if abuse or neglect has occurred

$\ldots$ it does not recur. This could mean removing a child from a dangerous situation permanently, it could mean removing the perpetrator, or it could

16 See Palm (2020:45-64). 
mean working with parents so that they are able to keep their child safe in future. Parents and families also need support to ensure that they can do their jobs. Reducing poverty (and hence the stress on families) is a key part of reducing child maltreatment, as is equipping parents with the skills for nonviolent forms of discipline. Reducing violence against South African children is both a moral imperative (to protect our children) and an imperative for national development. It can and must be achieved.

(lbid:3)

According to Mathews (2018:n.p.), “South Africa's response to both violence against women and children has, until now, been happening in silos. It's important that people start to join the dots. It makes sense to integrate approaches to both problems". She furthermore states in this regard that the

evidence showing what works on joint programmes to address violence against women and violence against children is only starting to emerge in low and middle-income settings. Successful programmes are targeting multiple stakeholders, challenging social norms about gender relations and the use of violence. At the same time, such programmes are also supporting greater communication and shared decision making among family members. (Ibid:n.p.)

South Africa is reckoned as a pathfinder country, and therefore part of the UN's Global Partnership to end violence against children (End violence against children n.p.). "If children are to reach their full potential and the cycle of intergenerational violence is to be broken, South Africa must consider collaborative solutions. Any programme of action must be aimed at preventing violence before it happens and providing an effective response and support to those affected by violence" (Mathews 2018:n.p.).

According to Brits (2018:n.p.), “[w]itnessing domestic violence and exposure to harsh physical punishment increases the chances of intimate partner violence in adulthood with men more likely to become perpetrators and women victims of violence". Therefore,

the state needs to provide a range of support services for parents and caregivers starting early in pregnancy. This includes income support (for example the child support grant), routine screening during antenatal care to identify and respond to risks such as maternal depression or domestic violence, and access to affordable child care.

(Ibid:n.p.)

The WHO (2020:n.p.) reasons that "responding to violence against children requires that efforts systematically address risk and protective factors at all four interrelated levels of risk (individual, relationship, community, society)". A group of ten international agencies under the leadership of the WHO (ibid:n.p.) "have developed and endorsed an evidence-based technical package called INSPIRE: Seven strategies for ending violence against children". This package

aims to help countries and communities achieve SDG Target 16.2 on ending violence against children. Each letter of the word INSPIRE stands for one of the 
strategies, and most have been shown to have preventive effects across several different types of violence, as well as benefits in areas such as mental health, education and crime reduction.

(Ibid:n.p.)

The seven strategies for ending violence against children are:

1. Implementation and enforcement of laws (for example, banning violent discipline and restricting access to alcohol and firearms);

2. Norms and values change (for example, altering norms that condone the sexual abuse of girls or aggressive behaviour amongst boys);

3. Safe environments (such as identifying neighbourhood "hot spots" for violence and then addressing the local causes through problem-oriented policing and other interventions);

4. Parental and caregiver support (for example, providing parent training to young, first time parents);

5. Income and economic strengthening (such as microfinance and gender equity training);

6. Response services provision (for example, ensuring that children who are exposed to violence can access effective emergency care and receive appropriate psychosocial support); and

7. Education and life skills (such as ensuring that children attend school and providing life and social skills training). WHO (2020 n.p.)

\section{CONCLUSION}

In this chapter, based on research by numerous scientists, practitioners, institutions, and studies over a long period of time, we focused on some of the most burning aspects of violence against children, namely physical, sexual, and emotional violence, as well as the impact of child negligence. We reflected on certain global and local perspectives on violence against children. This was followed by how violence is rooted in patriarchy and culture, and that we need more than just legislation to address this multipronged pandemic of violence. The chapter moved on by briefly looking into the difference faith-based communities can make in this respect and ends by seeking further solutions to combating violence in children's lives. 


\section{REFERENCES}

African Child Policy Forum. 2020. Sexual Exploitation of Children in Africa: A Silent Emergency. [Online]. https://bit.ly/3myifhr [Accessed 4 February 2021].

Brits, E. 2018. Only one in four children lives with both parents. GroundUp, 21 November. [Online]. https://bit.ly/ 31a4QE2 [Accessed 8 February 2021].

Burton, B., Ward, C., Artz, L. \& Leoschut, L. 2016. The Optimus Study on child abuse, violence and neglect in South Africa. Centre for Justice and Crime Prevention Research Bulletin: Cape Town. [Online]. https://bit. ly/3GCNRdZ [Accessed 4 February 2021].

Department of Basic Education. 2019. Comprehensive Sex Education. [Online]. https://bit.ly/2Y1QLay [Accessed 9 February 2021].

Council of Europe. 2017. Ending all forms of violence against children by 2030: The Council of Europe's contribution to the 2030 Agenda and the Sustainable Development Goals. [Online]. https://bit.ly/2ZI7RL1 [Accessed 9 February 2021].

Crouch, S.R., McNair, R. \& Waters, E. 2016. Impact of family structure and sociodemographic characteristics on child health and wellbeing in same-sex parent families: a cross-sectional survey. Journal of Paediatrics and Child Health, 52:499-505. https://doi.org/10.1111/jpc.13171 [Accessed 11 February 2021].

Crouch, S.R., Waters, E., McNair, R., Power, J. \& Davis, E. 2014. Parent-reported measures of child health and wellbeing in same-sex parent families: a cross-sectional survey. BMC Public Health, 14:635. [Online]. https://doi.org/10.1186/1471-2458-14-635 [Accessed 11 February 2021].

Dempsey D. 2013. Same-sex parented families in Australia. CFCA Paper No.18. Australian Institute of Family Studies: Melbourne. [Online]. https://bit. ly/3CLirQ0 [Accessed 11 February 2021].

Department of Health, Medical Research Council \& OrcMacro. 2007. South Africa Demographic and Health Survey 2003. Department of Health: Pretoria. [Online]. https://bit.ly/3nOUfGb [Accessed 8 February 2021].
End violence against children. 2021. Violence against children is preventable and the time to prevent it is now. [Online]. https://www.end-violence.org/ [Accessed 9 February 2021].

Fourie, L. 2020. Protecting children in the digital society. In: J. Grobbelaar \& C. Jones (eds.). Childhood Vulnerabilities in South Africa: Some Ethical Perspectives. African Sun Media: Stellenbosch. https://doi.org/ 10.18820/9781928480952/10

Fulu, E., McCook, S. \& Falb, K. 2017. What Works Evidence Review: Intersections of violence against women and violence against children. UKAid. [Online]. https://bit.ly/ 3nJtKCk [Accessed 8 February 2021].

Grobbelaar, J. \& Jones, C. 2020. The contentious issue of corporal punishment in South Africa. In: J. Grobbelaar \& C. Jones (eds.) Childhood Vulnerabilities in South Africa: Some Ethical Perspectives. African Sun Media: Stellenbosch. pp. 67-96. https:// doi.org/10.18820/9781928480952/03

Hall, K. \& Sambu, W. 2014. Income poverty, unemployment, and social grants. In: S. Mathews, L. Jamieson, L. Lake \& C. Smith (eds.). South African Child Gauge. Children's Institute, University of Cape Town: Cape Town. pp. 94-98.

Hall, K., Richter, L., Mokomane, Z. \& Lake, L. (eds.). 2018. South African Child Gauge 2018. Children's Institute, University of Cape Town: Cape Town. [Online]. http:// www.ci.uct.ac.za/ci/child-gauge/2018 [Accessed 8 February 2021].

Herring, D.J. 2014. Evolutionary Perspectives on Child Welfare Law. In: T.K. Shackelford \& Hansen, R.D. (eds.). The Evolution of Violence. Springer Science+Business Media: New York. https://doi.org/10.1007/978-14614-9314-3_4

Hillis, S., Mercy, J., Amobi, A. \& Kress, H. 2016. Global prevalence of past-year violence against children: A systematic review and minimum estimates. Pediatrics, 137(3):e20154079. [Online]. https://doi. org/10.1542/peds.2015-4079 [Accessed 11 February 2021].

Humanium. 2021. Children in the World: The global children's right situation by country. [Online]. https://bit.ly/3nPZ7uX [Accessed 9 February 2021]. 
Ipsos. 2017. Importance of religion or faith. Ipsos Global Trends. [Online]. https://bit. ly/3nFvw7a [Accessed 9 February 2021].

Jamieson, L., Mathews, S. \& Röhrs, S. 2018. Stopping family violence: Integrated approaches to address violence against women and children. In: K. Hall, L. Richter, Z. Mokkomane \& L. Lake (eds.). The South African Child Gauge 2018. Children's Institute, University of Cape Town: Cape Town. pp. 81-92.

Jewkes, R.K., Dunkle, K., Ndunad, M., Jamaa, P.N. \& Purene, A. 2010. Associations between childhood adversity and depression, substance abuse and HIV \& HSV2 incident infections in rural South African youth. Child Abuse \& Neglect, 34(11):833-841. https://doi.org/10.1016/j. chiabu.2010.05.002

Jones, C. 2019. Misbruik is endemies: Sterker morele toewyding kort. Die Burger, 19 Desember, p. 14.

Jones, O.D. 1997. Evolutionary analysis in law: An introduction and application to child abuse. North Carolina Law Review, 75:1117-1242.

Knight, K.W., Stephenson, S.E.M., West, S., Delatycki, M.B., Jones, C.A., Little, M.H., Patton, G.C., Sawyer, S.M., Skinner, S.R., Telfer, M.M., Wake, M., North, K.N. \& Oberklaid, F. 2017. The kids are OK: it is discrimination, not same-sex parents, that harms. MJA, 207(9):1-3. [Online]. https://bit.ly/3EDxrAh [Accessed 11 February 2021].

Kotch, J.B., Lewis, T., Hussey, J.M., English, D., Thompson, R., Litrownik, A.J., Runyan, D.K., Bangdiwala, S.I., Margolis, B. \& Dubowitz, H. 2008. Importance of early neglect for childhood aggression. Pediatrics, 121(4): 725-731. https://doi.org/10.1542/peds. 2 006-3622

Le Roux, L. 2020. Recognising and responding to complex dilemmas: Child marriage in South Africa. In: J. Grobbelaar \& C. Jones (eds.). Childhood Vulnerabilities in South Africa: Some Ethical Perspectives. African Sun Media: Stellenbosch. https://doi.org/ 10.18820/9781928480952/07

Manly, J.T., Kim, J.E., Rogosch, F.A. \& Cicchetti, D. 2001. Dimensions of child maltreatment and children's adjustment: Contributions of developmental timing and subtype.
Development and psychopathology, 13(04): 759-782. https://doi.org/10.1017/S0954 579401004023

Mathews, S. 2018. The link between violence against women and children matters. Here's why. The Conversation. [Online]. https:// bit.ly/3bte3sW [Accessed 8 February 2021].

Mathews, S. \& Benvenuti, P. 2014. Violence against children in South Africa: Developing a prevention agenda. In: S. Mathews, L. Jamieson, L. Lake \& C. Smith (eds.). The South African Child Gauge 2014. Children's Institute, University of Cape Town: Cape Town. pp. 26-34.

Mathews, S. \& Martin, L. 2016. Developing an understanding of fatal child abuse and neglect: Results from the South African child death review pilot study. South African Medical Journal, 106(12): 1160-1163. https://doi.org/10.7196/ SAMJ.2017.v106i12.12130

Miller, S. 2019. Corporal punishment of children fuels gender-based violence, Daily Maverick Citizen, 26 November, n.p. [Online]. https://bit.ly/3GFEme0 [Accessed 8 February 2021].

Palm, S. 2020. Seen but not heard? Engaging the mechanisms of faith to end violence against children. In: J. Grobbelaar \& C. Jones (eds.). Childhood Vulnerabilities in South Africa: Some Ethical Perspectives. African Sun Media: Stellenbosch. https:// doi.org/10.18820/9781928480952/02

Pew Research Center. 2011. A portrait of stepfamilies, Pew Social E Demographic Trends. [Online]. https://pewrsr.ch/ 2Y43BoV [Accessed 11 February 2021].

Richter, L.M., Matthews, S., Kagura, J. \& Nonterah, E. 2018. A longitudinal perspective on violence in the lives of South African children from the Birth to Twenty Plus cohort study in JohannesburgSoweto. South African Medical Journal, 108(3):181-186. https://doi.org/10.7196/ SAMJ.2017.v108i3.12661 [Accessed 5 February 2021].

Röhrs, S. 2019. Shifting attitudes and behaviours underpinning physical punishment of children. Briefing Paper, Children's Institute, University of Cape Town: Cape Town. 
Save the Children. 2017. Violence against children: The cost of inaction to our society and economy. Policy brief. [Online]. https:// bit.ly/3w1AfnA [Accessed 4 February 2021].

Stoltenborgh, M., Bakermans-Kranenburg, M. \& Van Ijzendoorn, M. 2013. The neglect of child neglect: A meta-analytic review of the prevalence of neglect. Social Psychiatry and Psychiatric Epidemiology. pp. 345-355. https://doi.org/10.1007/s00127-012-0549-y

The Constitution of the Republic of South Africa. 1996. Act 108 of 1996.

The Economist Intelligence Unit. 2020. Out of the shadows: Shining light on the response to child sexual abuse and exploitation, $A$ 60-country benchmarking index. [Online]. https://bit.ly/3bslh0z [Accessed 4. February 2021].

UNICEF. 2017. A familiar face: Violence in the lives of children $\mathcal{E}$ adolescents. UNICEF: New York.
Vijayalakshmi, A. 2015. Violent commercials: children's responses and parental mediation. Graduate Theses and Dissertations, 14444, Iowa State University Capstones. [Online]. https://lib.dr.iastate.edu/etd/14444 [Accessed 11 February 2021].

WHO (World Health Organization). 2020. Violence against children. [Online]. https:// bit.ly/3btRynN [Accessed 9 February 2021].

WHO (World Health Organization). 2006. Preventing child maltreatment: a guide to taking action and generating evidence. World Health Organization and International Society for Prevention of Child Abuse and Neglect: Geneva, Switzerland. [Online]. https://bit.ly/ 3nQeIL7 [Accessed 5 February 2021]. 